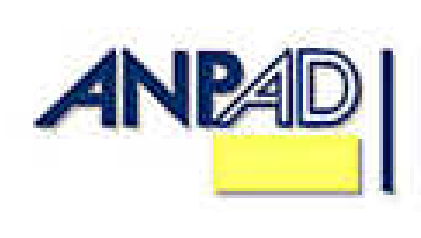
Disponível em http://www.anpad.org.br/rac
RAC, Curitiba, v. 13, n. 2, art. 7, p. 291-309, Abr./Jun. 2009

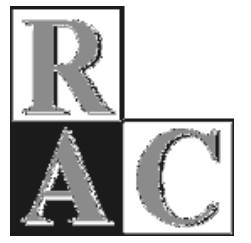

\title{
O Moving Average Convergence-Divergence como Ferramenta para a Decisão de Investimentos no Mercado de Ações
}

Moving Average Convergence-Divergence as a Tool for Deciding on Investments in the Stock Market

Rodrigo Silva Vidotto * Mestre em Engenharia de Produção pela EESC/USP. Professor da UNICEP, São Carlos/SP, Brasil.

Antônio Luiz Tonissi Migliato Mestre em Engenharia de Produção pela EESC/USP. Professor da PUC/Campinas, Campinas/SP, Brasil.

Antonio Carlos Zambon Doutor em Engenharia de Produção pelo DEP/UFSCAR. Professor da CESET/UNICAMP, Campinas/SP, Brasil.

* Endereço: Rodrigo Silva Vidotto

Rua Alameda das Cerejeiras, 48, São Carlos/SP, 13561-356. E-mail: rodrigovidotto@ hotmail.com

Copyright (C 2009 RAC. Todos os direitos, inclusive de tradução, são reservados. É permitido citar parte de artigos sem autorização prévia desde que seja identificada a fonte. 


\section{RESUMO}

O aumento do número de investidores na Bovespa desde o início da década de 2000 é decorrente da estabilização da inflação e da queda nas taxas de juros no período. A utilização de ferramentas que auxiliem os investidores nos processos de tomada de decisões é de suma importância em um mercado competitivo e arriscado. A análise técnica de ações é utilizada para identificar tendências nos movimentos dos preços das ações e assim indicar os momentos favoráveis para comprar ou vender ações. Dentre esses indicadores técnicos, há o Moving Average Convergence-Divergence [MACD], que utiliza o conceito de médias móveis em sua formulação e é considerada pelos analistas financeiros uma ferramenta simples de operar e interpretar. $\mathrm{O}$ objetivo deste artigo é avaliar a eficácia do MACD em indicar os momentos de compra e venda de ações de cinco empresas - escolhidas de forma aleatória - de um total de noventa empresas que integram o Novo Mercado da Bovespa e, analisar a rentabilidade auferida durante o ano de 2006, tendo como referencial a valorização do Ibovespa no ano de 2006. Nesse sentido, os resultados apurados mostram que a rentabilidade média acumulada das cinco ações foi de $26,7 \%$ contra uma rentabilidade média acumulada do Ibovespa de 0,90\%.

Palavras-chave: MACD; investidores; Novo Mercado; IBOVESPA.

\section{ABSTRACT}

The increase in the number of investors at Bovespa since 2000 is due to stabilized inflation and falling interest rates. The use of tools that assist investors in selling and buying stocks is very important in a competitive and risky market. The technical analysis of stocks is used to search for trends in the movements of share prices and therefore indicate a suitable moment to buy or sell stocks. Among these technical indicators is the Moving Average Convergence-Divergence [MACD], which uses the concept of moving average in its equation and is considered by financial analysts as a simple tool to operate and analyze. This article aims to assess the effectiveness of the use of the MACD to indicate the moment to purchase and sell stocks in five companies selected at random - a total of ninety companies in the Bovespa New Market and analyze the profitability gained during 2006, taking as a reference the valorization of the Ibovespa exchange in that year. The results show that the cumulative average return of the five companies was of $26.7 \%$ against a cumulative average return of $0.90 \%$ for Ibovespa.

Key words: MACD; investors; New Market; IBOVESPA. 


\section{INTRODUÇÃO}

A primeira década de 2000 tem-se mostrado promissora para a abertura de capital de empresas na bolsa de valores brasileira, visando à captação de recursos para a modernização/expansão de suas atividades produtivas.

Isso tem sido motivado particularmente pela estabilidade da economia brasileira, que envolve desde o controle da inflação na casa de um dígito anual, a valorização do Real perante o dólar, a queda contínua da taxa de juros (SELIC), entre outros.

Esses fatores não motivaram apenas as empresas a ingressarem na bolsa de valores, pois se verifica também um reflexo no aumento de novos investidores, que buscam novas formas de investimento, em detrimento da queda nas taxas de retorno de aplicações financeiras mais convencionais, como: Poupança, fundos de Renda Fixa e fundos DI.

Nesse sentido, a utilização de ferramentas que auxiliem os investidores a determinarem qual é o momento adequado para comprar e vender ações é de suma importância.

Atualmente, existem diversos indicadores utilizados pela análise técnica de ações, que auxiliam os investidores no processo de tomada de decisões, entre os quais, pode-se citar o Moving Average Convergence-Divergence [MACD], que será analisado neste artigo, Índice de Força Relativa, Médias Móveis, On balance Volume, etc. A funcionalidade dos indicadores técnicos será explicitada no tópico Análise Técnica de Ações.

Nesse sentido, o artigo delimita-se por desenvolver um estudo sobre a eficácia da utilização do MACD por investidores na compra e venda de ações e avaliar a valorização dessas ações entre o momento de compra e venda delas. Outra maneira de analisar se a valorização dos ativos foi satisfatória é compará-la com um referencial amplamente utilizado pelos analistas financeiros, que é a valorização do Índice Bovespa [IBOVESPA] no mesmo período.

A escolha pelo MACD se deu de forma aleatória dentre os diversos indicadores técnicos que compõe o grupo de indicadores denominados rastreadores de tendência e pela sua simplicidade no cálculo dos indicativos de compra e venda de ações.

Segundo Elder (2006) e Appel (2005), o MACD é capaz de produzir freqüentemente sinais precisos de compra e venda de ativos financeiros e é um dos melhores recursos de análise técnica para captar reversões.

Deve-se ressaltar que os indicadores não devem ser utilizados de forma isolada no processo de análise de uma ação para decidir qual é o momento adequado para se comprar ou vender uma ação, mas utilizá-los conjuntamente com outras ferramentas de análise técnica para corroborar o processo decisório.

\section{DEFINIÇÕES SOBRE O MERCADO DE CAPITAIS}

De acordo com Pinheiro (2005), o mercado de capitais é um conjunto de instituições que negociam com títulos e valores mobiliários, objetivando a canalização dos recursos dos agentes compradores para os agentes vendedores, ou seja, representa um sistema de distribuição de valores mobiliários que tem o propósito de viabilizar a capitalização das empresas e dar liquidez aos títulos emitidos por elas. 


\section{Novo Mercado}

O Novo Mercado é um segmento destinado à negociação de ações emitidas por empresas que, voluntariamente, adotam regras societárias adicionais, ampliando os direitos e melhorando a qualidade das informações prestadas pelas empresas.

Os níveis diferenciados de governança corporativa definem um conjunto de normas de conduta para empresas, administradores e controladores considerados importantes para uma boa valorização das ações das empresas (Pinheiro, 2005).

A melhoria da qualidade das informações prestadas pela Companhia e a ampliação dos direitos societários reduzem as incertezas no processo de avaliação e de investimento e, conseqüentemente, o risco de investir em tal empresa. (Bolsa de Valores de São Paulo [Bovespa], 2006).

\section{Índice Bovespa [IBOVESPA]}

O IBOVESPA é o mais importante indicador do desempenho médio das cotações do mercado de ações brasileiro, porque retrata o comportamento das principais ações negociadas na Bovespa.

Sua finalidade básica é a de servir como indicador médio do comportamento de mercado. Para tanto sua composição procura aproximar-se o mais possível da real configuração das negociações a vista (lote padrão) da Bovespa (Fortuna, 2002).

\section{Empresas Analisadas}

As cinco empresas analisadas, que representam 5,5\% das 90 empresas que compõem o Novo Mercado da Bovespa, foram sorteadas de forma aleatória. As empresas em questão são as seguintes: Banco do Brasil, Empresa Brasileira de Aeronáutica [Embraer], Natura, Perdigão Agroindustrial e Eletromotores WEG.

\section{ANÁLISE TÉCNICA DE AÇÕES}

A análise técnica de ações surgiu por volta do ano 1700, quando famílias japonesas passaram a acompanhar a variação do preço do arroz, com o intuito de formular tendências para tais oscilações. Esse método ficou conhecido como Candlesticks.

De acordo com Pinheiro (2005), a análise técnica é o estudo dos movimentos passados dos preços e dos volumes de negociação de ativos financeiros, com o objetivo de fazer previsões sobre comportamento futuro dos preços.

A análise técnica baseia-se no princípio de que os preços das ações, em determinada data futura, são influenciados pelos preços passados, sendo possível, então, prever a tendência de movimentação desses preços em determinado período de tempo.

A teoria de Charles Dow - que foi um dos expoentes na utilização da análise técnica - afirma que eventos passados podem determinar eventos futuros; a configuração gráfica dos preços tende a se relacionar com a direção que eles tomarão no futuro, ou seja, antes de um movimento significativo de alta ou baixa nas cotações de determinada ação, ocorrem formações que sinalizam previamente a movimentação que deverá ocorrer em relação a determinada ação.

Segundo Brum (2006), a análise técnica possui três premissas básicas das quais decorrem os estudos acerca do comportamento do mercado e suas tendências. 
1) Tudo pode ser resumido no preço das ações. Toda expectativa, boa ou má, dos investidores com relação a determinado ativo se reflete no preço diário daquele ativo.

2) Os preços movem-se por meio de tendências. Uma vez identificadas essas tendências por meio de gráficos, o investidor terá condições de operar de acordo com elas, porquanto, uma vez identificada essa tendência, é mais provável que ela continue do que reverta, o que não significa necessariamente que ela irá durar para sempre.

3) A história sempre se repete e que a compreensão de tendências futuras pode estar no estudo de acontecimentos passados.

\section{Análise Gráfica}

A análise gráfica é de extrema importância dentro do contexto da análise técnica de ações. A Análise gráfica apresenta uma série de figuras ou formações que denotam a formação de tendências e de pontos de reversão de um ativo financeiro.

Ela é fundamental para o market timing, ou seja, a escolha do momento certo para comprar ou vender a ação de determinada empresa (Fortuna, 2002).

Existem várias formas de gráficos utilizadas pelos analistas técnicos para se avaliar uma ação: Gráfico de linha, gráfico de volume, gráfico de barras, gráfico ponto-figura e gráfico Candlesticks.

Os gráficos podem indicar tendências, no sentido de mostrar a direção em que o mercado se movimenta, que pode ser: de alta, de baixa ou lateral.

Existem dois grupos de formações de tendências: as de continuação e as de reversão. As formações de continuação sugerem que a tendência continuará no mesmo sentido em que se encontra, enquanto as de reversão sugerem mudança no sentido da tendência.

\section{Indicadores Técnicos}

A utilização de indicadores técnicos na compreensão da movimentação dos preços dos ativos negociados na bolsa de valores é de suma importância. Os indicadores podem ajudar na identificação das tendências e de seus pontos de reversão.

Um problema que pode acontecer, ao se utilizar alguns indicadores técnicos, é de que, muitas vezes, eles se contradizem uns aos outros, pois alguns deles funcionam melhor em mercados sem tendência (osciladores) e, outros, em mercados com tendência (rastreadores) (Noronha, 1995).

Os rastreadores de tendências funcionam melhor, quando os mercados estão em alta ou em baixa, mas oferecem sinais precários e perigosos, quando os mercados estão na horizontal. Como exemplos, pode-se citar: Médias Móveis, Moving Average Convergence-Divergence [MACD], Histograma MACD, Sistema Direcional, On-Balance Volume [OBV], Acumulação/Distribuição e outros (Noronha, 1995).

Por sua vez, os osciladores captam pontos de inflexão nos mercados horizontais, mas emitem sinais prematuros e inseguros, quando os mercados começam a seguir determinada tendência. Entre os osciladores temos o Estocástico, Taxa de Mudança, Índice de Força Relativa [IFR], Elder-ray, Force Index e outros.

O objeto de estudo deste artigo é o rastreador de tendência conhecido como Moving Average Convergence-Divergence [MACD]. A escolha deste indicador deriva principalmente da sua facilidade de medição - decorrente da utilização de médias móveis - e da sua simplicidade na interpretação dos resultados apurados, pois os sinais de compra e venda são mostrados pelo cruzamento de duas linhas. 


\section{Médias Móveis}

A média móvel $[\mathrm{MM}]$ mostra o valor médio dos dados em determinado período, conforme equação da Figura 1. Uma MM de 5 dias mostra o valor médio dos últimos cinco dias. Uma MM de 20 dias mostra o preço médio dos últimos 20 dias, e assim por diante. Quando se conectam as médias móveis de cada dia, cria-se uma linha de média móvel.

Figura 1: Equação para o Cálculo da Média Móvel

$$
\mathrm{MM}=\frac{\mathrm{P}_{1}+\mathrm{P}_{2}+\ldots+\mathrm{P}_{\mathrm{N}}}{\mathrm{N}}
$$

Em que:

$\mathrm{P}=$ preço de que se está calculando a média

$\mathrm{N}$ = número de dias da média móvel (determinado pelo investidor)

De acordo com Appel (2005), as médias móveis são utilizadas para suavizar os ruídos das flutuações dos preços de curto prazo, de maneira que seja fácil identificar e definir tendências.

O valor da MM depende de dois fatores: os valores cuja média está sendo calculada e a amplitude do intervalo temporal desejado. Três são os tipos de médias móveis: simples, exponencial e ponderada.

A média móvel é uma fotografia composta do mercado - combina preços de vários dias. O mercado consiste em multidões enormes, e a média móvel identifica a direção do movimento da massa.

No caso de análise dos preços de ações, acredita-se que a média móvel simples não seja a mais indicada, pois muda duas vezes em resposta a cada dado. A média móvel exponencial [MME] é a melhor ferramenta de acompanhamento de tendência do que a média móvel simples. Ela atribui maior peso aos dados mais recentes e reage com mais rapidez às mudanças do que a MM simples. Ao mesmo tempo, a MME não salta em resposta a velhos dados. Verifica-se a equação da MME na Figura 2.

Figura 2: Fórmula para o Cálculo da Média Móvel Exponencial

$$
\mathrm{MME}=\mathrm{P}_{\text {hoje }} \mathrm{K}+\mathrm{MME}_{\text {ontem }} \bullet(1-\mathrm{K})
$$

$$
\begin{aligned}
& \text { Em que: } \quad \mathrm{K}=\frac{2}{\mathrm{~N}+1} \\
& \mathrm{~N}=\text { número de dias da MME (escolhido pelo investidor) } \\
& \mathrm{P}_{\text {hoje }}=\text { preço de hoje } \\
& \mathrm{MME}_{\text {ontem }}=\text { a MME de ontem }
\end{aligned}
$$

A utilização de médias móveis exponenciais é muito popular entre os analistas gráficos, em especial a utilização conjunta de duas médias móveis de períodos diferentes para aplicação de regra do cruzamento entre elas (Matsura, 2007). A média móvel é utilizada para o cálculo do MACD, por exemplo. 


\section{Moving Average Convergence-Divergence [MACD]}

O MACD, como ficou conhecido, foi desenvolvido por Gerald Appel, analista e gestor de recursos de terceiros em Nova Yorque. É um indicador que consiste em três médias móveis exponenciais e aparece nos gráficos como duas linhas, cujos cruzamentos emitem sinais de negociação (compra ou venda).

O indicador compõe-se de duas linhas: uma linha denominada MACD e outra linha denominada linha de sinal. A linha MACD é composta de duas médias móveis exponenciais. Ela responde às mudanças nos preços com relativa rapidez. A linha de sinal é composta pela linha MACD, ajustada por outra MME. Ela responde às mudanças nos preços com mais lentidão (Elder, 2004).

Os sinais de compra e venda são emitidos quando a linha MACD (linha cheia) mais rápida cruza acima ou abaixo da linha de sinal (linha tracejada) mais lenta. Neste caso, quando a linha MACD cruza para baixo a linha de sinal, é indicativo de venda da ação analisada; quando a linha MACD cruza para cima a linha de sinal, é indicativo de compra desta mesma ação.

Este indicador é construído da seguinte maneira (Elder, 2004):

1) Calcular a MME de 12 dias dos preços de fechamento.

2) Calcular a MME de 26 dias dos preços de fechamento.

3) Subtrair a MME de 26 dias da MME de 12 dias e plotar a diferença como uma linha azul. Essa é a linha MACD.

4) Calcular a MME de 9 dias da linha rápida e plotar o resultado como uma linha vermelha. Essa é a linha de sinal lenta.

\section{Empresas Analisadas}

As empresas escolhidas para análise neste artigo são: Banco do Brasil (BBAS3) - Setor financeiro; Embraer (EMBR3) - Setor Industrial; Natura (NATU3) - Setor de Consumo e Varejo; Perdigão (PRGA3) - Setor Consumo e Varejo; e WEG (WEGE3) - Setor Industrial. As ações das cinco empresas analisadas - aproximadamente 5,5\% do total de empresas que compõem o Novo Mercado da Bovespa - foram sorteadas de um total de noventa empresas, usando-se o método de amostragem aleatória simples, cuja finalidade é escolher amostra de uma população, tal que qualquer item da população tenha a mesma probabilidade de ser selecionado. Este tipo de amostragem requer que todos os itens da população estejam disponíveis para serem avaliados na amostra (Freund \& Simon, 2000).

Para cada empresa foi analisado a movimentação do MACD no ano de 2006 com intuito de observar o cruzamento das linhas (MACD e a linha de sinal) e detectar o momento de compra e venda dessas ações. Para tanto será utilizado um gráfico com o MACD e uma tabela com os seguintes valores indicativos: data (onde ocorre o cruzamento das linhas), ordem (de compra ou venda), preço de fechamento da ação no dia, variação \% (que ocorreu entre o momento da compra e o momento da venda), IBOVESPA (valor do fechamento do dia) e variação IBOVESPA \% (que ocorreu entre o momento da compra e o momento da venda). 


\section{Banco do Brasil}

O Banco do Brasil é a maior instituição financeira do País, atendendo a todos os segmentos do mercado financeiro. Atualmente, o Banco do Brasil possui 24,6 milhões de clientes correntistas, 15,1 mil pontos de atendimentos em 3,1 mil cidades e está presente em 22 países. O faturamento bruto do Banco do Brasil em 2006 foi de aproximadamente R $\$ 37$ bilhões (Banco do Brasil, 2007).

De acordo com os indicativos de compra e venda da Figura 3 e as variações percentuais apresentadas na Tabela 1, para o Banco do Brasil, o MACD ofereceu um indicativo favorável de compra e venda em $57 \%$ dos casos e em $43 \%$ dos casos o indicativo foi desfavorável.

Um investidor que seguisse os indicativos de compra e venda do MACD obteria uma rentabilidade acumulada, de 44,11\% contra uma rentabilidade acumulada do IBOVESPA de 9,71\% no mesmo período.

\section{Figura 3: MACD (BBAS3)}

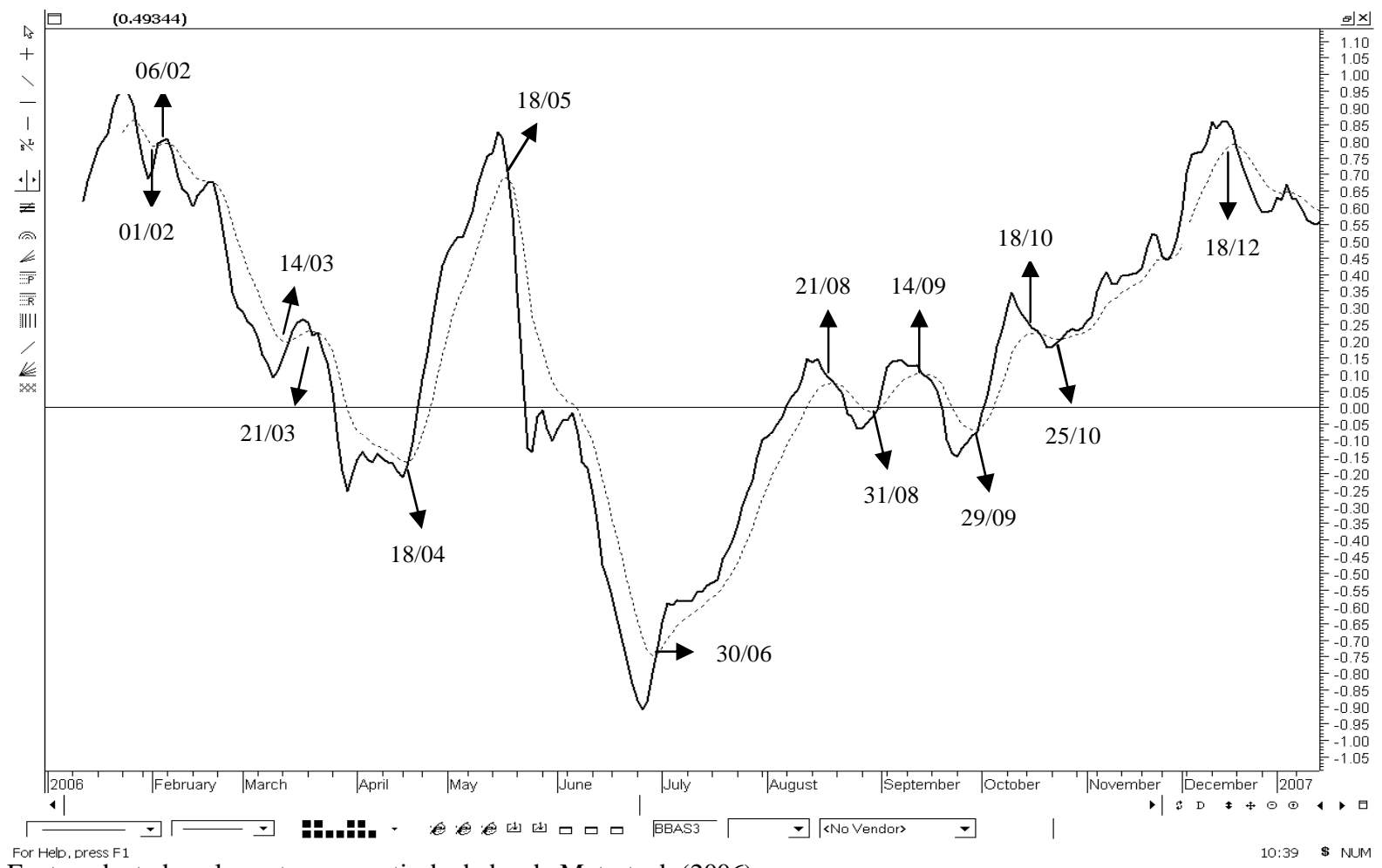

Fonte: adaptado pelos autores a partir de dados do Metastock (2006). 
Tabela 1: Ordens de Compra e Venda - Banco do Brasil

\begin{tabular}{|c|c|c|c|c|c|}
\hline \multicolumn{6}{|c|}{ BBAS3 } \\
\hline Data & Ordem & $\begin{array}{c}\text { Preço } \\
\text { fechamento }\end{array}$ & $\begin{array}{c}\text { Variação \% } \\
(\mathbf{C} / \mathbf{V})\end{array}$ & IBOVESPA & $\begin{array}{c}\text { Variação \% } \\
\text { (IBOVESPA) }\end{array}$ \\
\hline $1 / 2 / 06$ & Compra & $\mathrm{R} \$ 17,02$ & \multirow{2}{*}{$2,23 \%$} & 38.484 & \multirow{2}{*}{$-3,02 \%$} \\
\hline $6 / 2 / 06$ & Venda & $\mathrm{R} \$ 17,40$ & & 37.321 & \\
\hline $14 / 3 / 06$ & Compra & $\mathrm{R} \$ 17,60$ & \multirow{2}{*}{$-3,35 \%$} & 37.541 & \multirow{2}{*}{$-0,38 \%$} \\
\hline $21 / 3 / 06$ & Venda & $\mathrm{R} \$ 17,01$ & & 37.398 & \\
\hline $18 / 4 / 06$ & Compra & $\mathrm{R} \$ 16,40$ & \multirow{2}{*}{$15,00 \%$} & 39.572 & \multirow{2}{*}{$-4,46 \%$} \\
\hline $18 / 5 / 06$ & Venda & $\mathrm{R} \$ 18,86$ & & 37.807 & \\
\hline $30 / 6 / 06$ & Compra & $\mathrm{R} \$ 15,46$ & \multirow{2}{*}{$-1,16 \%$} & 36.412 & \multirow{2}{*}{$2,05 \%$} \\
\hline $21 / 8 / 06$ & Venda & $\mathrm{R} \$ 15,28$ & & 37.160 & \\
\hline $31 / 8 / 06$ & Compra & $\mathrm{R} \$ 15,44$ & \multirow{2}{*}{$-0,19 \%$} & 36.232 & \multirow{2}{*}{$-0,22 \%$} \\
\hline $14 / 9 / 06$ & Venda & $\mathrm{R} \$ 15,41$ & & 36.153 & \\
\hline $29 / 9 / 06$ & Compra & $\mathrm{R} \$ 15,28$ & \multirow{2}{*}{$6,09 \%$} & 36.449 & \multirow{2}{*}{$6,13 \%$} \\
\hline $18 / 10 / 06$ & Venda & $\mathrm{R} \$ 16,21$ & & 38.685 & \\
\hline $25 / 10 / 06$ & Compra & $\mathrm{R} \$ 16,56$ & \multirow{2}{*}{$21,20 \%$} & 39.562 & \multirow{2}{*}{$9,97 \%$} \\
\hline $18 / 12 / 06$ & Venda & $\mathrm{R} \$ 20,07$ & & 43.508 & \\
\hline & $\%$ acumu & & $44,11 \%$ & & $9,71 \%$ \\
\hline
\end{tabular}

Fonte: simulação elaborada pelos autores a partir dos indicativos de compra e venda do Metastock (2006).

\section{Embraer}

A Empresa Brasileira de Aeronáutica S.A. [Embraer] é uma das maiores empresas aeroespaciais do mundo. Com mais de 38 anos de existência, a empresa já produziu cerca de 4.100 aviões, que hoje operam em 69 países. A Embraer foi a maior exportadora brasileira entre os anos de 1999 e 2001, e foi a segunda maior empresa exportadora nos anos de 2002, 2003 e 2004. O faturamento bruto da Embraer em 2006 foi de aproximadamente R \$ 7,3 bilhões (Embraer, 2007).

De acordo com os indicativos de compra e venda da Figura 4 e as variações percentuais apresentadas na Tabela 2, para a Embraer, o MACD ofereceu um indicativo favorável de compra e venda em 44,4\% dos casos e em 55,6\% dos casos o indicativo foi desfavorável.

Um investidor que seguisse os indicativos de compra e venda do MACD obteria uma rentabilidade acumulada, de 7,06\% contra uma rentabilidade acumulada do IBOVESPA de $-8,66 \%$ no mesmo período. 


\section{Figura 4: MACD (EMBR3)}

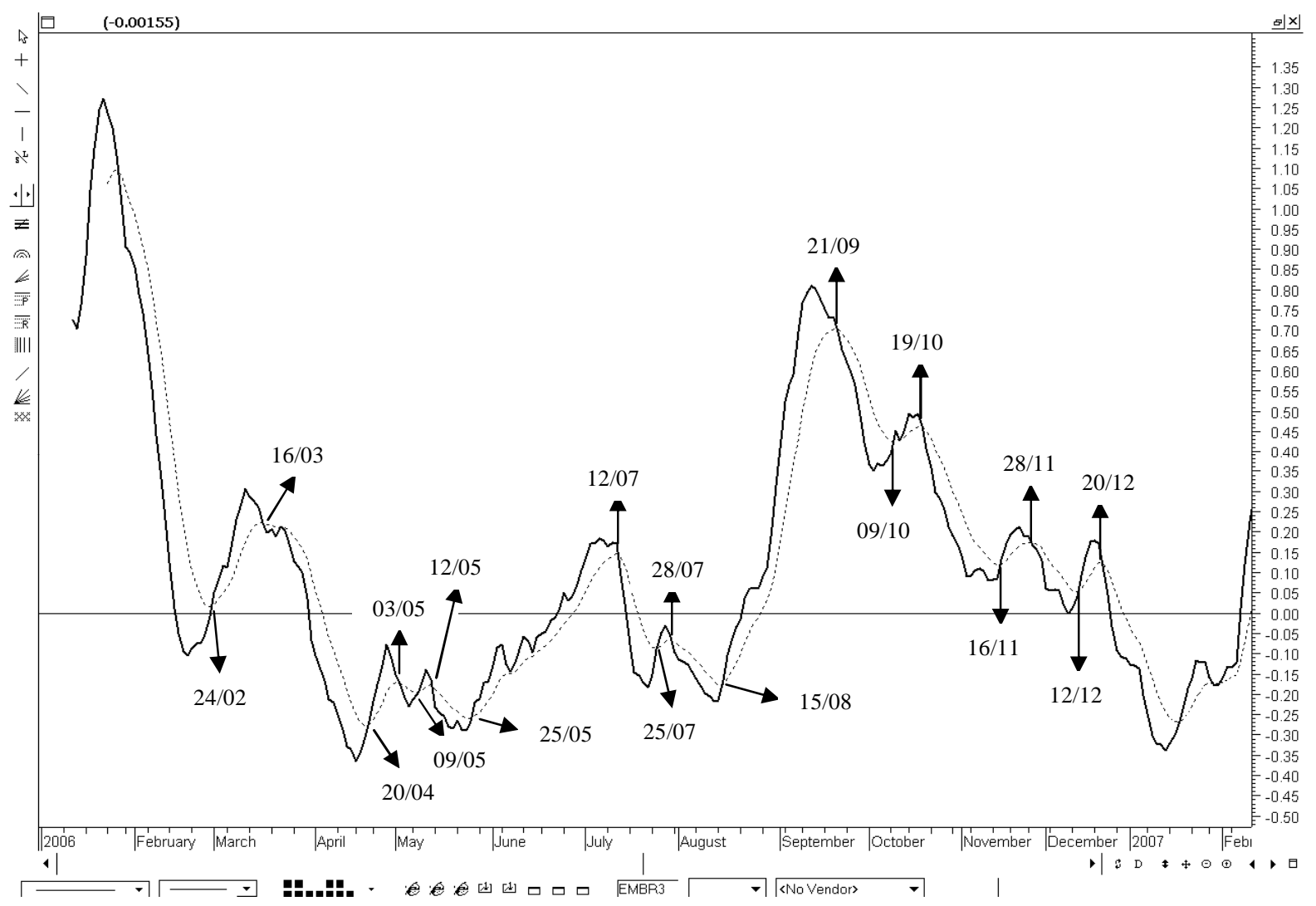

Fonte: adaptado pelos autores a partir de dados do Metastock (2006).

Tabela 2: Ordens de Compra e Venda - Embraer

\begin{tabular}{|c|c|c|c|c|c|}
\hline \multicolumn{6}{|c|}{ EMBR3 } \\
\hline Data & Ordem & $\begin{array}{c}\text { Preço } \\
\text { fechamento }\end{array}$ & $\begin{array}{c}\text { Variação \% } \\
(\mathbf{C} / \mathrm{V})\end{array}$ & IBOVESPA & $\begin{array}{c}\text { Variação \% } \\
\text { (IBOVESPA) }\end{array}$ \\
\hline $24 / 2 / 06$ & Compra & $\mathrm{R} \$ 19,95$ & \multirow{2}{*}{$075 \%$} & 38.610 & \multirow{2}{*}{$-1,18 \%$} \\
\hline $16 / 3 / 06$ & Venda & $\mathrm{R} \$ 20,10$ & & 38.156 & \\
\hline $20 / 4 / 06$ & Compra & $\mathrm{R} \$ 19,36$ & \multirow{2}{*}{$-3,15 \%$} & 39.774 & \multirow{2}{*}{$2,88 \%$} \\
\hline $3 / 5 / 06$ & Venda & $\mathrm{R} \$ 18,75$ & & 40.919 & \\
\hline $9 / 5 / 06$ & Compra & $\mathrm{R} \$ 18,94$ & \multirow{2}{*}{$-2,06 \%$} & 41.979 & \multirow{2}{*}{$-4,21 \%$} \\
\hline $12 / 5 / 06$ & Venda & $\mathrm{R} \$ 18,55$ & & 40.211 & \\
\hline $25 / 5 / 06$ & Compra & $\mathrm{R} \$ 18,42$ & \multirow{2}{*}{$4,67 \%$} & 37.568 & \multirow{2}{*}{$-3,56 \%$} \\
\hline $12 / 7 / 06$ & Venda & $\mathrm{R} \$ 19,28$ & & 36.229 & \\
\hline $25 / 7 / 06$ & Compra & $\mathrm{R} \$ 19,11$ & \multirow{2}{*}{$-3,87 \%$} & 36.680 & \multirow{2}{*}{$1,91 \%$} \\
\hline $28 / 7 / 06$ & Venda & $\mathrm{R} \$ 18,37$ & & 37.381 & \\
\hline $15 / 8 / 06$ & Compra & $\mathrm{R} \$ 18,46$ & \multirow{2}{*}{$16,36 \%$} & 37.295 & \multirow{2}{*}{$-6,61 \%$} \\
\hline $21 / 9 / 06$ & Venda & $\mathrm{R} \$ 21,48$ & & 34.830 & \\
\hline $9 / 10 / 06$ & Compra & $\mathrm{R} \$ 22,05$ & \multirow{2}{*}{$0,91 \%$} & 38.460 & \multirow{2}{*}{$1,34 \%$} \\
\hline 19/10/06 & Venda & $\mathrm{R} \$ 22,25$ & & 39.919 & \\
\hline $16 / 11 / 06$ & Compra & $\mathrm{R} \$ 22,59$ & \multirow{2}{*}{$-1,81 \%$} & 41.161 & \multirow{2}{*}{$-0,29 \%$} \\
\hline 28/11/06 & Venda & $\mathrm{R} \$ 22,18$ & & 41.043 & \\
\hline $12 / 12 / 06$ & Compra & $\mathrm{R} \$ 22,49$ & \multirow{2}{*}{$-3,42 \%$} & 43.018 & \multirow{2}{*}{$1,13 \%$} \\
\hline $20 / 12 / 06$ & Venda & $\mathrm{R} \$ 21,72$ & & 43.502 & \\
\hline \multicolumn{3}{|c|}{$\%$ acumulada } & $7,07 \%$ & & $-8,66 \%$ \\
\hline
\end{tabular}

Fonte: simulação elaborada pelos autores a partir dos indicativos de compra e venda do Metastock (2006). 


\section{Natura}

A Natura foi fundada em 1969 no Brasil e pertence ao setor de cosméticos e produtos de higiene e de perfumaria. O faturamento bruto da Natura em 2006 foi de aproximadamente R \$ 3,9 bilhões (Natura, 2007).

De acordo com os indicativos de compra e venda da Figura 5 e as variações percentuais apresentadas na Tabela 3, para a Natura, o MACD ofereceu um indicativo favorável de compra e venda em 54,5\% dos casos e em $45,5 \%$ dos casos o indicativo foi desfavorável.

Um investidor que seguisse os indicativos de compra e venda do MACD obteria uma rentabilidade acumulada, de $13,93 \%$ contra uma rentabilidade acumulada do IBOVESPA de 0,87\% no mesmo período.

Figura 5: MACD (NATU3)

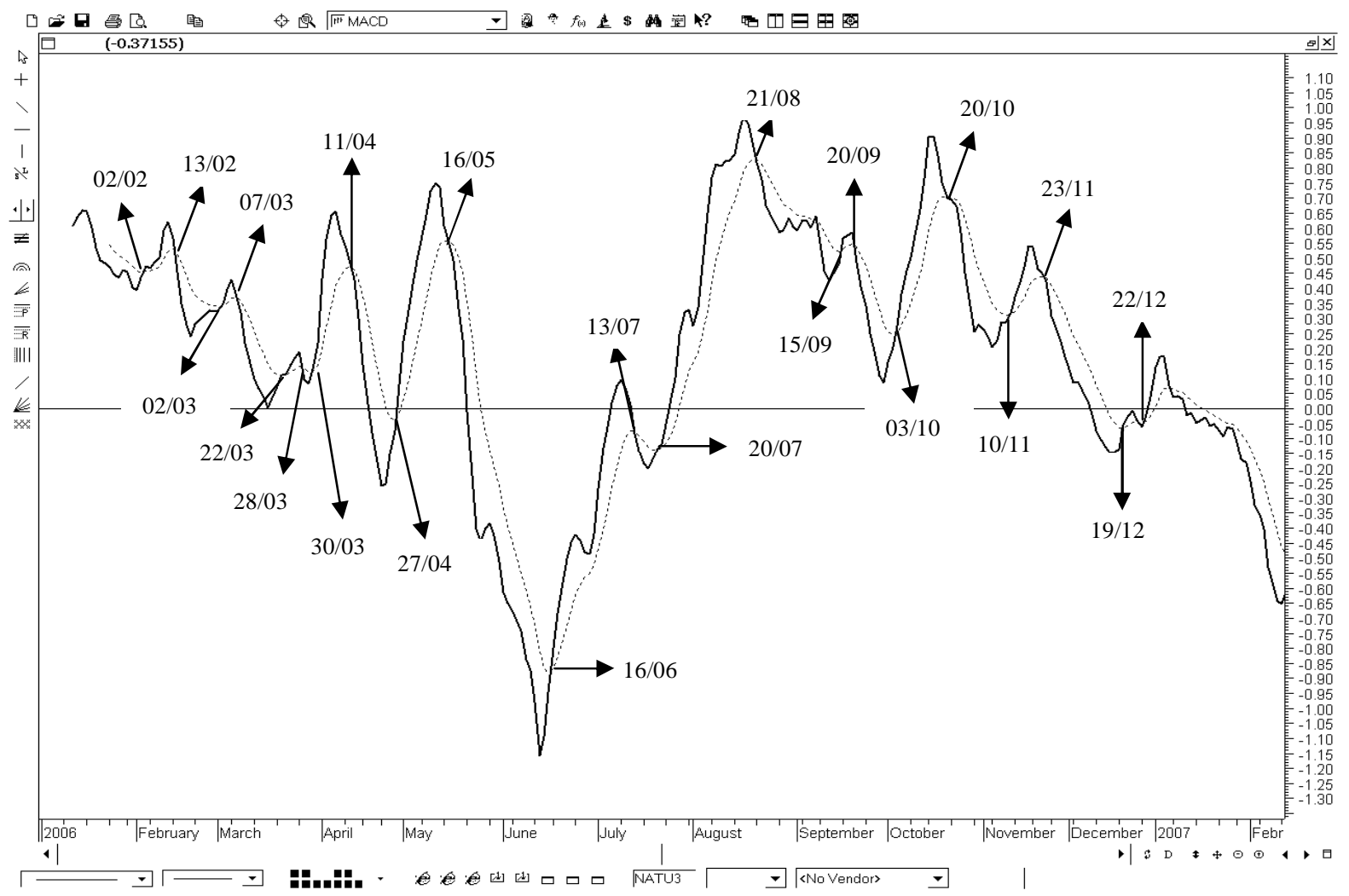

Fonte: Metastock. Adaptado pelos autores a partir de dados do Metastock (2006).

Tabela 3: Ordens de Compra e Venda - Natura

\begin{tabular}{|c|c|c|c|c|c|}
\hline \multicolumn{6}{|c|}{ NATU3 } \\
\hline Data & Ordem & $\begin{array}{c}\text { Preço } \\
\text { fechamento }\end{array}$ & $\begin{array}{c}\text { Variação \% } \\
\text { (C/V) }\end{array}$ & IBOVESPA & $\begin{array}{c}\text { Variação \% } \\
\text { (IBOVESPA) }\end{array}$ \\
\hline $2 / 2 / 06$ & Compra & $\mathrm{R} \$ 22,87$ & \multirow{2}{*}{$-0,39 \%$} & 37.304 & \multirow{2}{*}{$-3,19 \%$} \\
\hline $13 / 2 / 06$ & Venda & $\mathrm{R} \$ 22,78$ & & 36.113 & \\
\hline $2 / 3 / 06$ & Compra & $\mathrm{R} \$ 23,52$ & \multirow{2}{*}{$-2,55 \%$} & 39.125 & \multirow{2}{*}{$-4,35 \%$} \\
\hline $7 / 3 / 06$ & Venda & $\mathrm{R} \$ 22,92$ & & 37.422 & \\
\hline $22 / 3 / 06$ & Compra & $\mathrm{R} \$ 23,01$ & \multirow{2}{*}{$-4,00 \%$} & 37.850 & \multirow{2}{*}{$-3,09 \%$} \\
\hline $28 / 3 / 06$ & Venda & $\mathrm{R} \$ 22,09$ & & 36.682 & \\
\hline $30 / 3 / 06$ & Compra & $\mathrm{R} \$ 23,68$ & \multirow{2}{*}{$2,58 \%$} & 37.776 & \multirow{2}{*}{$0,33 \%$} \\
\hline $11 / 4 / 06$ & Venda & $\mathrm{R} \$ 24,29$ & & 37.901 & \\
\hline
\end{tabular}


(conclusão)

Tabela 3: Ordens de Compra e Venda - Natura

\begin{tabular}{|c|c|c|c|c|c|}
\hline \multicolumn{6}{|c|}{ NATU3 } \\
\hline Data & Ordem & $\begin{array}{c}\text { Preço } \\
\text { fechamento }\end{array}$ & $\begin{array}{c}\text { Variação \% } \\
(\mathrm{C} / \mathrm{V})\end{array}$ & IBOVESPA & $\begin{array}{c}\text { Variação \% } \\
\text { (IBOVESPA) }\end{array}$ \\
\hline $27 / 4 / 06$ & Compra & $\mathrm{R} \$ 24,05$ & \multirow{2}{*}{$4,74 \%$} & 39.751 & \multirow{2}{*}{$-0,84 \%$} \\
\hline $16 / 5 / 06$ & Venda & $\mathrm{R} \$ 25,19$ & & 39.416 & \\
\hline $16 / 6 / 06$ & Compra & $\mathrm{R} \$ 21,69$ & \multirow{2}{*}{$-4,75 \%$} & 34.398 & \multirow{2}{*}{$2,78 \%$} \\
\hline $13 / 7 / 06$ & Venda & $\mathrm{R} \$ 20,66$ & & 35.354 & \\
\hline $20 / 7 / 06$ & Compra & $\mathrm{R} \$ 21,78$ & \multirow{2}{*}{$15,15 \%$} & 35.846 & \multirow{2}{*}{$3,67 \%$} \\
\hline $21 / 08 / 06$ & Venda & $\mathrm{R} \$ 25,08$ & & 37.160 & \\
\hline $15 / 9 / 06$ & Compra & $\mathrm{R} \$ 26,72$ & \multirow{2}{*}{$1,24 \%$} & 36.169 & \multirow{2}{*}{$-2,69 \%$} \\
\hline $20 / 9 / 06$ & Venda & $\mathrm{R} \$ 27,05$ & & 35.196 & \\
\hline $3 / 10 / 06$ & Compra & $\mathrm{R} \$ 26,82$ & \multirow{2}{*}{$5,29 \%$} & 36.437 & \multirow{2}{*}{$6,05 \%$} \\
\hline $20 / 10 / 06$ & Venda & $\mathrm{R} \$ 28,24$ & & 38.642 & \\
\hline $10 / 11 / 06$ & Compra & $\mathrm{R} \$ 28,83$ & \multirow{2}{*}{$1,39 \%$} & 40.719 & \multirow{2}{*}{$3,32 \%$} \\
\hline $23 / 11 / 06$ & Venda & $\mathrm{R} \$ 29,23$ & & 42.069 & \\
\hline 19/12/06 & Compra & $\mathrm{R} \$ 29,00$ & \multirow{2}{*}{$-4,00 \%$} & 43.589 & \multirow{2}{*}{$-0,54 \%$} \\
\hline $22 / 12 / 06$ & Venda & $\mathrm{R} \$ 27,84$ & & 43.355 & \\
\hline \multicolumn{3}{|c|}{$\%$ acumulada } & $13,93 \%$ & & $0,87 \%$ \\
\hline
\end{tabular}

Fonte: simulação elaborada pelos autores a partir dos indicativos de compra e venda do Metastock (2006).

\section{Perdigão}

A Perdigão é uma das maiores companhias de alimentos da América Latina e está entre as principais empregadoras do Brasil, com cerca de 40 mil funcionários. Fundada em 1934, em Santa Catarina, a empresa opera unidades industriais em cinco Estados brasileiros e sua presença internacional supera a marca de cem países. O faturamento bruto da Perdigão foi de $\mathrm{R} \$ 6,1$ bilhões em 2006 (Perdigão, 2007).

De acordo com os indicativos de compra e venda da Figura 6 e as variações percentuais apresentadas na Tabela 4, para a Perdigão, o MACD ofereceu um indicativo favorável de compra e venda em 50\% dos casos e em $50 \%$ dos casos o indicativo foi desfavorável. 
Figura 6: MACD (PRGA3)

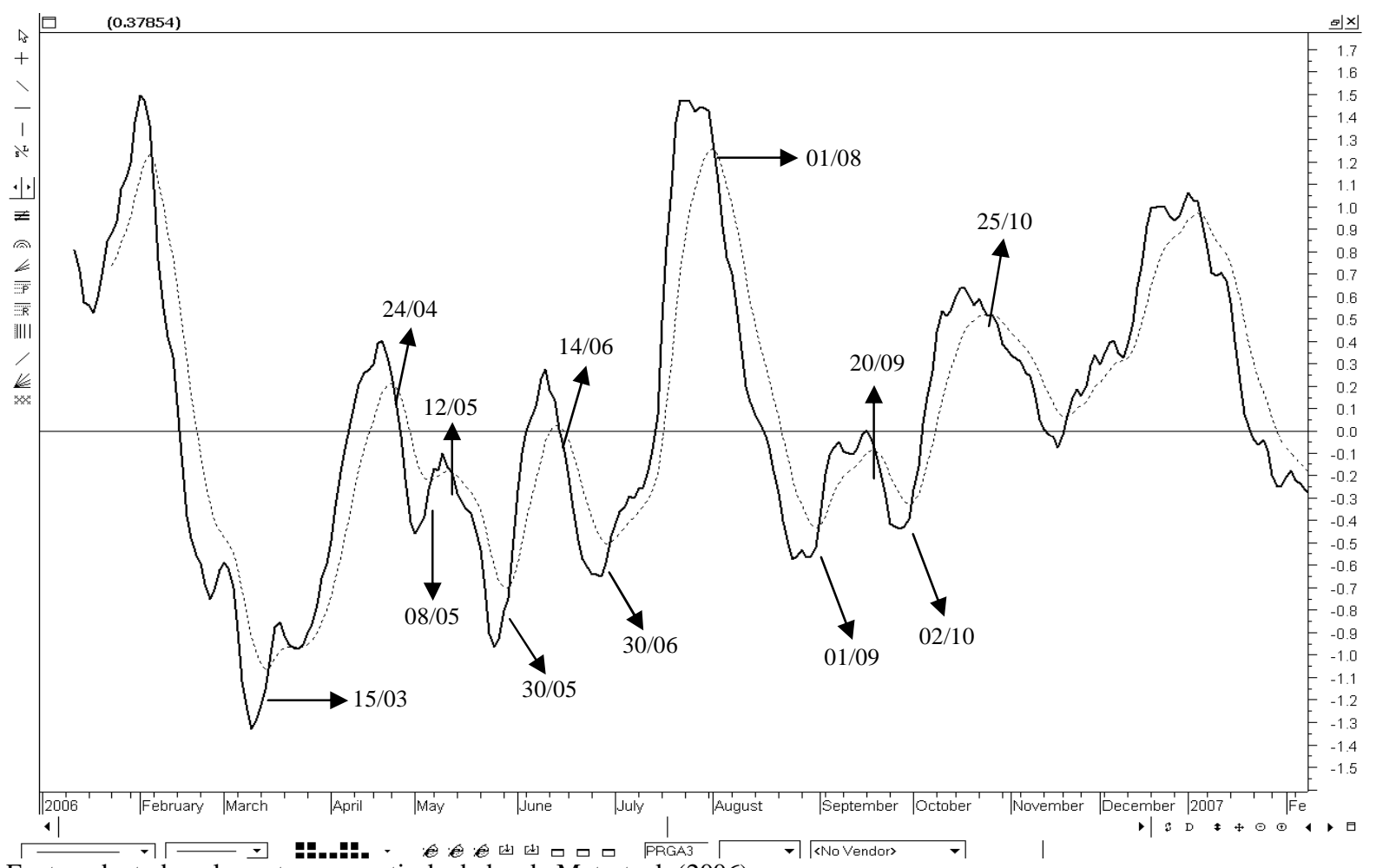

Fonte: adaptado pelos autores a partir de dados do Metastock (2006).

Tabela 4: Ordens de Compra e Venda - Perdigão

\begin{tabular}{|c|c|c|c|c|c|}
\hline \multicolumn{6}{|c|}{ PRGA3 } \\
\hline Data & Ordem & $\begin{array}{c}\text { Preço } \\
\text { fechamento }\end{array}$ & $\begin{array}{c}\text { Variação \% } \\
\text { (C/V) }\end{array}$ & IBOVESPA & $\begin{array}{l}\text { Variação \% } \\
\text { (IBOVESPA) }\end{array}$ \\
\hline $15 / 3 / 06$ & Compra & $\mathrm{R} \$ 23,83$ & \multirow{2}{*}{$-1,89 \%$} & 38.243 & \multirow{2}{*}{$3,94 \%$} \\
\hline $24 / 4 / 06$ & Venda & $\mathrm{R} \$ 23,38$ & & 39.751 & \\
\hline $8 / 5 / 06$ & Compra & $\mathrm{R} \$ 23,76$ & \multirow{2}{*}{$-5,77 \%$} & 41.515 & \multirow{2}{*}{$-3,14 \%$} \\
\hline $12 / 5 / 06$ & Venda & $\mathrm{R} \$ 22,39$ & & 40.211 & \\
\hline $30 / 5 / 06$ & Compra & $\mathrm{R} \$ 20,57$ & \multirow{2}{*}{$0,68 \%$} & 36.412 & \multirow{2}{*}{$-9,53 \%$} \\
\hline $14 / 6 / 06$ & Venda & $\mathrm{R} \$ 20,71$ & & 32.941 & \\
\hline $30 / 6 / 06$ & Compra & $\mathrm{R} \$ 21,21$ & \multirow{2}{*}{$18,58 \%$} & 36.630 & \multirow{2}{*}{$0,57 \%$} \\
\hline $1 / 8 / 06$ & Venda & $\mathrm{R} \$ 25,15$ & & 36.839 & \\
\hline $1 / 9 / 06$ & Compra & $\mathrm{R} \$ 23,48$ & \multirow{2}{*}{$-6,30 \%$} & 37.329 & \multirow{2}{*}{$-5,71 \%$} \\
\hline $20 / 9 / 06$ & Venda & $\mathrm{R} \$ 22,00$ & & 35.196 & \\
\hline $2 / 10 / 06$ & Compra & $\mathrm{R} \$ 23,18$ & \multirow{2}{*}{$6,38 \%$} & 37.057 & \multirow{2}{*}{$6,76 \%$} \\
\hline $25 / 10 / 06$ & Venda & $\mathrm{R} \$ 24,66$ & & 39.562 & \\
\hline \multicolumn{3}{|c|}{$\%$ acumulada } & $10,02 \%$ & & $-7,80 \%$ \\
\hline
\end{tabular}

Fonte: simulação elaborada pelos autores a partir dos indicativos de compra e venda do Metastock (2006).

\section{WEG}

Maior fabricante latino-americana de motores elétricos e uma das maiores do mundo, a WEG atua nas áreas de comando e proteção, variação de velocidade, automação de processos industriais, geração e distribuição de energia e tintas e vernizes industriais.

A WEG possui mais de 15 mil funcionários em todo o mundo e teve um faturamento bruto de $\mathrm{R} \$ 3,5$ bilhões em 2006 (WEG, 2007). 
De acordo com os indicativos de compra e venda da Figura 7 e as variações percentuais apresentadas na Tabela 5, para a empresa WEG, o MACD ofereceu um indicativo favorável de compra e venda em $85,7 \%$ dos casos e em $14,3 \%$ dos casos o indicativo foi desfavorável.

Figura 7: MACD (WEGE3)

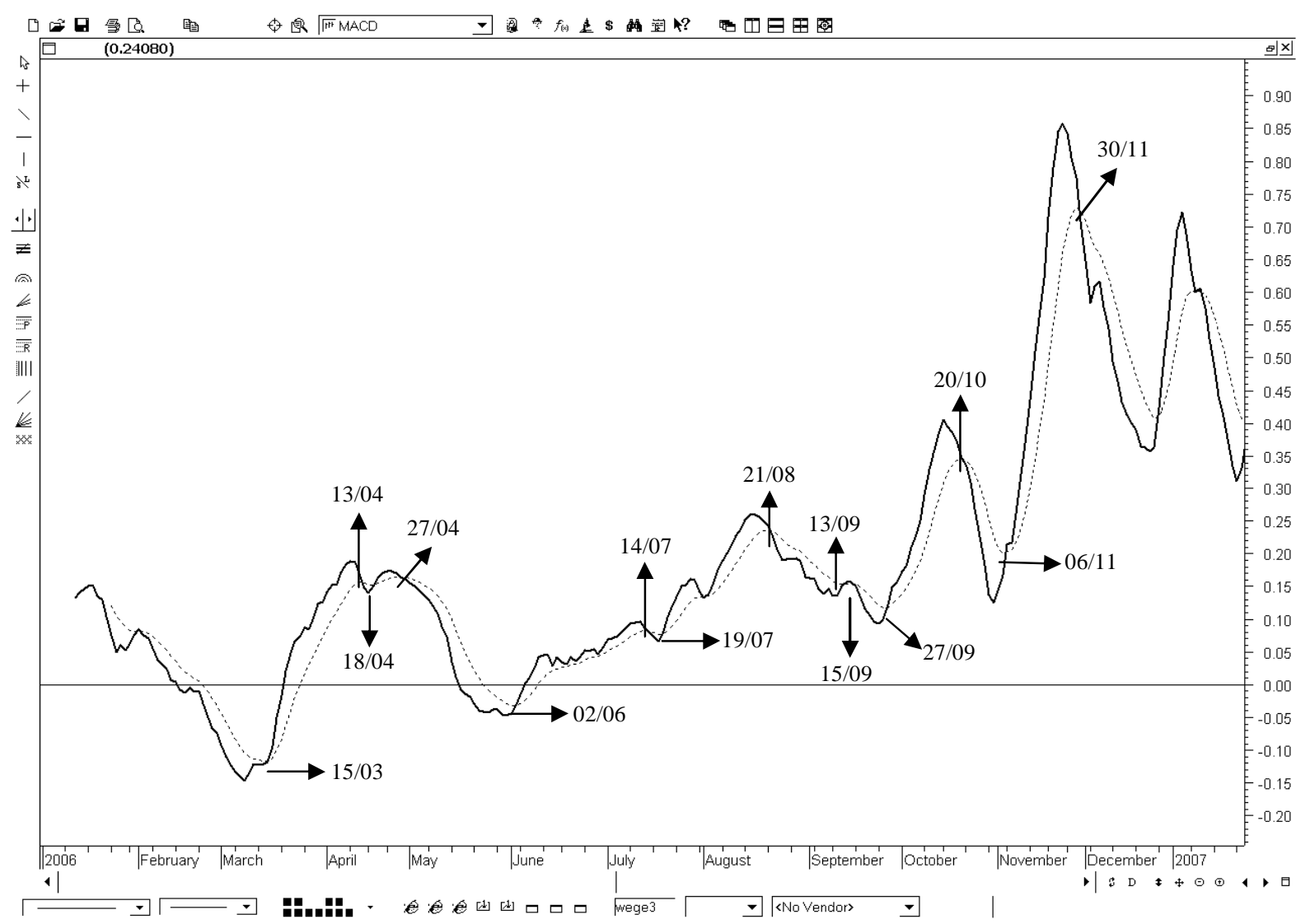

Fonte: Metastock. Adaptado pelos autores a partir de dados do Metastock (2006).

Tabela 5: Ordens de Compra e Venda - WEG

\begin{tabular}{|c|c|c|c|c|c|}
\hline \multicolumn{6}{|c|}{ WEGE3 } \\
\hline Data & Ordem & $\begin{array}{c}\text { Preço } \\
\text { fechamento }\end{array}$ & $\begin{array}{c}\text { Variação \% } \\
\text { (C/V) }\end{array}$ & IBOVESPA & $\begin{array}{c}\text { Variação \% } \\
\text { (IBOVESPA) }\end{array}$ \\
\hline $15 / 3 / 06$ & Compra & $\mathrm{R} \$ 6,61$ & \multirow{2}{*}{$11,20 \%$} & 38.243 & \multirow{2}{*}{$-0,42 \%$} \\
\hline $13 / 4 / 06$ & Venda & $\mathrm{R} \$ 7,35$ & & 38.082 & \\
\hline 18/4/06 & Compra & $\mathrm{R} \$ 7,77$ & \multirow{2}{*}{$0,13 \%$} & 39.572 & \multirow{2}{*}{$0,45 \%$} \\
\hline $27 / 4 / 06$ & Venda & $\mathrm{R} \$ 7,78$ & & 39.751 & \\
\hline $2 / 6 / 06$ & Compra & $\mathrm{R} \$ 7,54$ & \multirow{2}{*}{$4,64 \%$} & 37.942 & \multirow{2}{*}{$-6,83 \%$} \\
\hline $14 / 7 / 06$ & Venda & $\mathrm{R} \$ 7,89$ & & 35.349 & \\
\hline 19/7/06 & Compra & $\mathrm{R} \$ 8,12$ & \multirow{2}{*}{$10,96 \%$} & 36.785 & \multirow{2}{*}{$1,02 \%$} \\
\hline $21 / 8 / 06$ & Venda & $\mathrm{R} \$ 9,01$ & & 37.160 & \\
\hline 13/09/06 & Compra & $\mathrm{R} \$ 9,40$ & \multirow{2}{*}{$-0,96 \%$} & 36.549 & \multirow{2}{*}{$-1,04 \%$} \\
\hline $15 / 9 / 06$ & Venda & $\mathrm{R} \$ 9,31$ & & 36.169 & \\
\hline $27 / 9 / 06$ & Compra & $\mathrm{R} \$ 9,59$ & \multirow{2}{*}{$8,13 \%$} & 36.105 & \multirow{2}{*}{$7,03 \%$} \\
\hline $20 / 10 / 06$ & Venda & $\mathrm{R} \$ 10,37$ & & 38.642 & \\
\hline $6 / 11 / 06$ & Compra & $\mathrm{R} \$ 11,10$ & \multirow{2}{*}{$14,41 \%$} & 41.246 & \multirow{2}{*}{$1,66 \%$} \\
\hline $30 / 11 / 06$ & Venda & $\mathrm{R} \$ 12,70$ & & 41.931 & \\
\hline \multicolumn{3}{|c|}{ \% acumulada } & $58,41 \%$ & & $1,37 \%$ \\
\hline
\end{tabular}

Fonte: simulação elaborada pelos autores a partir dos indicativos de compra e venda do Metastock (2006). 
Um investidor que seguisse os indicativos de compra e venda do MACD obteria uma rentabilidade acumulada, de 58,41\% contra uma rentabilidade acumulada do IBOVESPA de 1,37\% no mesmo período.

\section{Simulação de Dados}

Este tópico visa simular, a partir de um valor hipotético - $\mathrm{R} \$ 1.000$, a valorização das ações das empresas analisadas, caso um investidor tivesse levado em conta os indicativos de compra e venda do MACD. Para tanto foi confrontada a rentabilidade acumulada de cada ação versus a rentabilidade acumulada do IBOVESPA durante o ano de 2006.

Para a simulação dos cálculos foram desconsideradas as taxas referentes à corretagem, emolumentos e custódia que incidem nas operações de compra e venda de ações. Também foi considerado que o valor obtido pela venda da ação é o mesmo que será reaplicado no indicativo de compra subseqüente.

\section{Banco do Brasil}

Tabela 6: Simulação de Compra e Venda - Banco do Brasil

\begin{tabular}{|c|c|c|c|c|c|}
\hline \multicolumn{6}{|c|}{ BBAS3 } \\
\hline Data & Ordem & $\begin{array}{c}\text { Valor } \\
\text { investido }\end{array}$ & $\begin{array}{c}\text { Variação \% } \\
(\mathrm{C} / \mathrm{V})\end{array}$ & $\begin{array}{c}\text { Valor } \\
\text { investido }\end{array}$ & $\begin{array}{c}\text { Variação \% } \\
\text { (IBOVESPA) }\end{array}$ \\
\hline $1 / 2 / 06$ & Compra & $\mathrm{R} \$ 1.000,00$ & \multirow{2}{*}{$2,23 \%$} & $\mathrm{R} \$ 1.000,00$ & \multirow{2}{*}{$-3,02 \%$} \\
\hline $6 / 2 / 06$ & Venda & $\mathrm{R} \$ 1.022,30$ & & $\mathrm{R} \$ 969,80$ & \\
\hline $14 / 3 / 06$ & Compra & $\mathrm{R} \$ 1.022,30$ & \multirow{2}{*}{$-3,35 \%$} & $\mathrm{R} \$ 969,80$ & \multirow{2}{*}{$-0,38 \%$} \\
\hline $21 / 3 / 06$ & Venda & $\mathrm{R} \$ 988,05$ & & $\mathrm{R} \$ 966,11$ & \\
\hline $18 / 4 / 06$ & Compra & $\mathrm{R} \$ 988,05$ & \multirow{2}{*}{$15,00 \%$} & $\mathrm{R} \$ 966,11$ & \multirow{2}{*}{$-4,46 \%$} \\
\hline $18 / 5 / 06$ & Venda & $\mathrm{R} \$ 1.136,26$ & & $\mathrm{R} \$ 923,02$ & \\
\hline $30 / 6 / 06$ & Compra & $\mathrm{R} \$ 1.136,26$ & \multirow{2}{*}{$-1,16 \%$} & $\mathrm{R} \$ 923,02$ & \multirow{2}{*}{$2,05 \%$} \\
\hline $21 / 08 / 06$ & Venda & $\mathrm{R} \$ 1.123,08$ & & $\mathrm{R} \$ 941,94$ & \\
\hline $31 / 8 / 06$ & Compra & $\mathrm{R} \$ 1.123,08$ & \multirow{2}{*}{$-0,19 \%$} & $\mathrm{R} \$ 941,94$ & \multirow{2}{*}{$-0,22 \%$} \\
\hline $14 / 9 / 06$ & Venda & $\mathrm{R} \$ 1.120,95$ & & $\mathrm{R} \$ 939,87$ & \\
\hline $29 / 9 / 06$ & Compra & $\mathrm{R} \$ 1.120,95$ & \multirow{2}{*}{$6,09 \%$} & $\mathrm{R} \$ 939,87$ & \multirow{2}{*}{$6,13 \%$} \\
\hline $18 / 10 / 06$ & Venda & $\mathrm{R} \$ 1.189,21$ & & $\mathrm{R} \$ 997,48$ & \\
\hline $25 / 10 / 06$ & Compra & $\mathrm{R} \$ 1.189,21$ & \multirow{2}{*}{$21,20 \%$} & $\mathrm{R} \$ 997,48$ & \multirow{2}{*}{$9,97 \%$} \\
\hline $18 / 12 / 06$ & Venda & $\mathrm{R} \$ 1.141,20$ & & $\mathrm{R} \$ 1.096,93$ & \\
\hline \multicolumn{3}{|c|}{$\%$ acumulada } & $44,11 \%$ & & $9,71 \%$ \\
\hline
\end{tabular}

Fonte: simulação elaborada pelos autores a partir dos indicativos de compra e venda do Metastock (2006).

Como demonstrado na Tabela 6, se um investidor tivesse aplicado $\mathrm{R} \$ 1.000$ nas ações do Banco do Brasil (BBAS3) em 01/02/06 e as tivesse vendido em 18/12/06 obteria uma rentabilidade de 44,28\% ( $\mathrm{R} \$ 1.441,20)$ contra uma rentabilidade de 9,69\% (R \$ 1.096,93) de uma suposta carteira de ações que segue a valorização do IBOVESPA.

\section{Embraer}

Tabela 7: Simulação de Compra e Venda - Embraer

\begin{tabular}{|c|c|c|c|c|c|}
\hline \multicolumn{6}{|c|}{ EMBR3 } \\
\hline Data & Ordem & $\begin{array}{c}\text { Valor } \\
\text { investido }\end{array}$ & $\begin{array}{c}\text { Variação \% } \\
\text { (C/V) }\end{array}$ & $\begin{array}{c}\text { Valor } \\
\text { investido }\end{array}$ & $\begin{array}{c}\text { Variação \% } \\
\text { (IBOVESPA) }\end{array}$ \\
\hline $24 / 2 / 06$ & Compra & $\mathrm{R} \$ 1.000,00$ & \multirow{2}{*}{$0,75 \%$} & $\mathrm{R} \$ 1.000,00$ & \multirow{2}{*}{$-1,18 \%$} \\
\hline $16 / 3 / 06$ & Venda & $\mathrm{R} \$ 1.007,50$ & & $\mathrm{R} \$ 988,20$ & \\
\hline $20 / 4 / 06$ & Compra & $\mathrm{R} \$ 1.007,50$ & \multirow{2}{*}{$-3,15 \%$} & $\mathrm{R} \$ 988,20$ & \multirow{2}{*}{$2,88 \%$} \\
\hline $3 / 5 / 06$ & Venda & $\mathrm{R} \$ 975,76$ & & $\mathrm{R} \$ 1.016,66$ & \\
\hline 9/5/06 & Compra & $\mathrm{R} \$ 975,76$ & \multirow{2}{*}{$-2,06 \%$} & $\mathrm{R} \$ 1.016,66$ & \multirow{2}{*}{$-4,21 \%$} \\
\hline $12 / 5 / 06$ & Venda & $\mathrm{R} \$ 955,66$ & & $\mathrm{R} \$ 973,86$ & \\
\hline
\end{tabular}


(conclusão)

Tabela 7: Simulação de Compra e Venda - Embraer

\begin{tabular}{|c|c|c|c|c|c|}
\hline \multicolumn{6}{|c|}{ EMBR3 } \\
\hline Data & Ordem & $\begin{array}{c}\text { Valor } \\
\text { investido }\end{array}$ & $\begin{array}{c}\text { Variação \% } \\
\text { (C/V) }\end{array}$ & $\begin{array}{c}\text { Valor } \\
\text { investido }\end{array}$ & $\begin{array}{c}\text { Variação \% } \\
\text { (IBOVESPA) }\end{array}$ \\
\hline $25 / 5 / 06$ & Compra & $\mathrm{R} \$ 955,66$ & \multirow{2}{*}{$4,67 \%$} & $\mathrm{R} \$ 973,86$ & \multirow{2}{*}{$-3,56 \%$} \\
\hline $12 / 7 / 06$ & Venda & $\mathrm{R} \$ 1.00,18$ & & $\mathrm{R} \$ 939,19$ & \\
\hline $25 / 7 / 06$ & Compra & $\mathrm{R} \$ 1.000,18$ & \multirow{2}{*}{$-3,87 \%$} & $\mathrm{R} \$ 939,19$ & \multirow{2}{*}{$1,91 \%$} \\
\hline $28 / 7 / 06$ & Venda & $\mathrm{R} \$ 961,47$ & & $\mathrm{R} \$ 957,13$ & \\
\hline $15 / 8 / 06$ & Compra & $\mathrm{R} \$ 961,47$ & \multirow{2}{*}{$16,36 \%$} & $\mathrm{R} \$ 957,13$ & \multirow{2}{*}{$-6,61 \%$} \\
\hline $21 / 9 / 06$ & Venda & $\mathrm{R} \$ 1.118,77$ & & $\mathrm{R} \$ 893,86$ & \\
\hline $9 / 10 / 06$ & Compra & $\mathrm{R} \$ 1.118,77$ & \multirow{2}{*}{$0,91 \%$} & $\mathrm{R} \$ 893,86$ & \multirow{2}{*}{$1,34 \%$} \\
\hline $19 / 10 / 06$ & Venda & $\mathrm{R} \$ 1.128,95$ & & $\mathrm{R} \$ 905,84$ & \\
\hline $16 / 11 / 06$ & Compra & $\mathrm{R} \$ 1.128,95$ & \multirow{2}{*}{$-1,81 \%$} & $\mathrm{R} \$ 905,84$ & \multirow{2}{*}{$-0,29 \%$} \\
\hline $28 / 11 / 06$ & Venda & $\mathrm{R} \$ 1.108,52$ & & $\mathrm{R} \$ 903,21$ & \\
\hline $12 / 12 / 06$ & Compra & $\mathrm{R} \$ 1.180,52$ & \multirow{2}{*}{$-3,42 \%$} & $\mathrm{R} \$ 903,21$ & \multirow{2}{*}{$1,13 \%$} \\
\hline $20 / 12 / 06$ & Venda & $\mathrm{R} \$ 1.070,70$ & & $\mathrm{R} \$ 913,42$ & \\
\hline \multicolumn{3}{|c|}{$\%$ acumulada } & $7,07 \%$ & & $-8,66 \%$ \\
\hline
\end{tabular}

Fonte: simulação elaborada pelos autores a partir dos indicativos de compra e venda do Metastock (2006).

De acordo com a Tabela 7, se um investidor tivesse aplicado R \$ 1.000 nas ações da Embraer (EMBR3) em 24/02/06 e as tivesse vendido em 20/12/06 obteria uma rentabilidade de 7,07\% (R\$ $1.070,70)$ contra uma rentabilidade negativa de $8,66 \%(\mathrm{R} \$ 913,42)$ de uma suposta carteira de ações que segue a valorização do IBOVESPA.

\section{Natura}

Tabela 8: Simulação de Compra e Venda - Natura

\begin{tabular}{|c|c|c|c|c|c|}
\hline \multicolumn{6}{|c|}{ NATU3 } \\
\hline Data & Ordem & $\begin{array}{c}\text { Valor } \\
\text { investido }\end{array}$ & $\begin{array}{c}\text { Variação \% } \\
\text { (C/V) }\end{array}$ & $\begin{array}{c}\text { Valor } \\
\text { investido }\end{array}$ & $\begin{array}{c}\text { Variação \% } \\
\text { (IBOVESPA) }\end{array}$ \\
\hline $2 / 2 / 06$ & Compra & $\mathrm{R} \$ 1.000,00$ & \multirow{2}{*}{$-0,39 \%$} & $\mathrm{R} \$ 1.000,00$ & \multirow{2}{*}{$-3,19 \%$} \\
\hline $13 / 2 / 06$ & Venda & $\mathrm{R} \$ 996,10$ & & $\mathrm{R} \$ 968,10$ & \\
\hline $2 / 3 / 06$ & Compra & $\mathrm{R} \$ 996,10$ & \multirow{2}{*}{$-2,55 \%$} & $\mathrm{R} \$ 968,10$ & \multirow{2}{*}{$-4,35 \%$} \\
\hline $7 / 3 / 06$ & Venda & $\mathrm{R} \$ 970,70$ & & $\mathrm{R} \$ 925,99$ & \\
\hline $22 / 3 / 06$ & Compra & $\mathrm{R} \$ 970,70$ & \multirow{2}{*}{$-4,00 \%$} & $\mathrm{R} \$ 925,99$ & \multirow{2}{*}{$-3,09 \%$} \\
\hline $28 / 3 / 06$ & Venda & $\mathrm{R} \$ 931,87$ & & $\mathrm{R} \$ 897,38$ & \\
\hline $30 / 3 / 06$ & Compra & $\mathrm{R} \$ 931,87$ & \multirow{2}{*}{$2,58 \%$} & $\mathrm{R} \$ 897,38$ & \multirow{2}{*}{$0,33 \%$} \\
\hline $11 / 4 / 06$ & Venda & $\mathrm{R} \$ 955,91$ & & $\mathrm{R} \$ 900,34$ & \\
\hline $27 / 4 / 06$ & Compra & $\mathrm{R} \$ 955,91$ & \multirow{2}{*}{$4,74 \%$} & $\mathrm{R} \$ 900,34$ & \multirow{2}{*}{$-0,84 \%$} \\
\hline $16 / 5 / 06$ & Venda & $\mathrm{R} \$ 1.001,22$ & & $\mathrm{R} \$ 892,78$ & \\
\hline $16 / 6 / 06$ & Compra & $\mathrm{R} \$ 1.001,22$ & \multirow{2}{*}{$-4,75 \%$} & $\mathrm{R} \$ 892,78$ & \multirow{2}{*}{$2,78 \%$} \\
\hline $13 / 7 / 06$ & Venda & $\mathrm{R} \$ 953,66$ & & $\mathrm{R} \$ 917,60$ & \\
\hline $20 / 7 / 06$ & Compra & $\mathrm{R} \$ 953,66$ & \multirow{2}{*}{$15,15 \%$} & $\mathrm{R} \$ 917,60$ & \multirow{2}{*}{$3,67 \%$} \\
\hline $21 / 8 / 06$ & Venda & $\mathrm{R} \$ 1.098,14$ & & $\mathrm{R} \$ 951,27$ & \\
\hline $15 / 9 / 06$ & Compra & $\mathrm{R} \$ 1.098,14$ & \multirow{2}{*}{$1,24 \%$} & $\mathrm{R} \$ 951,27$ & \multirow{2}{*}{$-2,69 \%$} \\
\hline $20 / 9 / 06$ & Venda & $\mathrm{R} \$ 1.111,76$ & & $\mathrm{R} \$ 925,68$ & \\
\hline $3 / 10 / 06$ & Compra & $\mathrm{R} \$ 1.111,76$ & \multirow[t]{2}{*}{$5,29 \%$} & $\mathrm{R} \$ 925,68$ & \multirow{2}{*}{$6,05 \%$} \\
\hline 20/10/06 & Venda & $\mathrm{R} \$ 1.170,57$ & & $\mathrm{R} \$ 981,68$ & \\
\hline $10 / 11 / 06$ & Compra & $\mathrm{R} \$ 1.170,57$ & \multirow[t]{2}{*}{$1,39 \%$} & $\mathrm{R} \$ 981,68$ & \multirow{2}{*}{$3,32 \%$} \\
\hline $23 / 11 / 06$ & Venda & $\mathrm{R} \$ 1.186,84$ & & $\mathrm{R} \$ 1.014,27$ & \\
\hline 19/12/06 & Compra & $\mathrm{R} \$ 1.186,84$ & \multirow[t]{2}{*}{$-4,00 \%$} & $\mathrm{R} \$ 1.014,27$ & \multirow{2}{*}{$-0,54 \%$} \\
\hline $22 / 12 / 06$ & Venda & $\mathrm{R} \$ 1.139,37$ & & $\mathrm{R} \$ 1.008,79$ & \\
\hline \multicolumn{3}{|c|}{$\%$ acumulada } & $13,93 \%$ & & $0,87 \%$ \\
\hline
\end{tabular}

Fonte: simulação elaborada pelos autores a partir dos indicativos de compra e venda do Metastock (2006). 
Como visto na Tabela 8, se um investidor tivesse aplicado R \$ 1.000 nas ações da Natura (NATU3) em 02/02/06 e as tivesse vendido em 22/12/06 obteria uma rentabilidade de 13,93\% (R $\$ 1.139,37$ ) contra uma rentabilidade de $0,87 \%$ ( $\$$ \$ $1.008,79)$ de uma suposta carteira de ações que segue a valorização do IBOVESPA.

\section{Perdigão}

Tabela 9: Simulação de Compra e Venda - Perdigão

\begin{tabular}{|c|c|c|c|c|c|}
\hline \multicolumn{6}{|c|}{ PRGA3 } \\
\hline Data & Ordem & $\begin{array}{c}\text { Valor } \\
\text { investido }\end{array}$ & $\begin{array}{c}\text { Variação \% } \\
\text { (C/V) }\end{array}$ & $\begin{array}{c}\text { Valor } \\
\text { investido }\end{array}$ & $\begin{array}{c}\text { Variação \% } \\
\text { (IBOVESPA) }\end{array}$ \\
\hline $15 / 3 / 06$ & Compra & $\mathrm{R} \$ 1.000,00$ & \multirow{2}{*}{$-1,89 \%$} & $\mathrm{R} \$ 1.000,00$ & \multirow{2}{*}{$3,94 \%$} \\
\hline $24 / 4 / 06$ & Venda & $\mathrm{R} \$ 981,10$ & & $\mathrm{R} \$ 1.039,40$ & \\
\hline $8 / 5 / 06$ & Compra & $\mathrm{R} \$ 981,10$ & \multirow{2}{*}{$-5,77 \%$} & $\mathrm{R} \$ 1.039,40$ & \multirow{2}{*}{$-3,14 \%$} \\
\hline $12 / 5 / 06$ & Venda & $\mathrm{R} \$ 924,49$ & & $\mathrm{R} \$ 1.006,76$ & \\
\hline $30 / 5 / 06$ & Compra & $\mathrm{R} \$ 924,49$ & \multirow{2}{*}{$0,68 \%$} & $\mathrm{R} \$ 1.006,76$ & \multirow{2}{*}{$-9,53 \%$} \\
\hline $14 / 6 / 06$ & Venda & $\mathrm{R} \$ 930,78$ & & $\mathrm{R} \$ 910,81$ & \\
\hline $30 / 6 / 06$ & Compra & $\mathrm{R} \$ 930,78$ & \multirow{2}{*}{$18,58 \%$} & $\mathrm{R} \$ 910,81$ & \multirow{2}{*}{$0,57 \%$} \\
\hline $1 / 8 / 06$ & Venda & $\mathrm{R} \$ 1.103,72$ & & $\mathrm{R} \$ 916,00$ & \\
\hline $1 / 9 / 06$ & Compra & $\mathrm{R} \$ 1.103,72$ & \multirow{2}{*}{$-6,30 \%$} & $\mathrm{R} \$ 916,00$ & \multirow{2}{*}{$-5,71 \%$} \\
\hline $20 / 9 / 06$ & Venda & $\mathrm{R} \$ 1.034,18$ & & $\mathrm{R} \$ 863,70$ & \\
\hline $2 / 10 / 06$ & Compra & $\mathrm{R} \$ 1.034,18$ & \multirow{2}{*}{$6,38 \%$} & $\mathrm{R} \$ 863,70$ & \multirow{2}{*}{$6,76 \%$} \\
\hline $25 / 10 / 06$ & Venda & $\mathrm{R} \$ 1.100,16$ & & $\mathrm{R} \$ 922,10$ & \\
\hline \multicolumn{3}{|c|}{$\%$ acumulada } & $10,02 \%$ & & $-7,80 \%$ \\
\hline
\end{tabular}

Fonte: simulação elaborada pelos autores a partir dos indicativos de compra e venda do Metastock (2006).

Como se demonstra na Tabela 9, se um investidor tivesse aplicado R $\$ 1.000$ nas ações da Perdigão (PRGA3) em 15/03/06 e as tivesse vendido em 25/10/06 obteria uma rentabilidade de 10,02\% (R\$ $1.100,16)$ contra uma rentabilidade negativa de $7,80 \%$ (R $\$ 922,10)$ de uma suposta carteira de ações que segue a valorização do IBOVESPA.

\section{WEG}

Tabela 10: Simulação de Compra e Venda - WEG

\begin{tabular}{|c|c|c|c|c|c|}
\hline \multicolumn{6}{|c|}{ WEGE3 } \\
\hline Data & Ordem & $\begin{array}{c}\text { Preço } \\
\text { fechamento }\end{array}$ & $\begin{array}{c}\text { Variação \% } \\
(\mathrm{C} / \mathrm{V})\end{array}$ & IBOVESPA & $\begin{array}{l}\text { Variação \% } \\
\text { (IBOVESPA) }\end{array}$ \\
\hline $15 / 3 / 06$ & Compra & $\mathrm{R} \$ 1.000,00$ & \multirow{2}{*}{$11,20 \%$} & $\mathrm{R} \$ 1.000,00$ & \multirow{2}{*}{$-0,42 \%$} \\
\hline $13 / 4 / 06$ & Venda & $\mathrm{R} \$ 1.112,00$ & & $\mathrm{R} \$ 995,80$ & \\
\hline $18 / 4 / 06$ & Compra & $\mathrm{R} \$ 1.112,00$ & \multirow{2}{*}{$0,13 \%$} & $\mathrm{R} \$ 995,80$ & \multirow{2}{*}{$0,45 \%$} \\
\hline $27 / 4 / 06$ & Venda & $\mathrm{R} \$ 1.113,44$ & & $\mathrm{R} \$ 1.000,28$ & \\
\hline $2 / 6 / 06$ & Compra & $\mathrm{R} \$ 1.113,44$ & \multirow{2}{*}{$4,64 \%$} & $\mathrm{R} \$ 1.000,28$ & \multirow{2}{*}{$-6,83 \%$} \\
\hline $14 / 7 / 06$ & Venda & $\mathrm{R} \$ 1.165,11$ & & $\mathrm{R} \$ 931,96$ & \\
\hline $19 / 7 / 06$ & Compra & $\mathrm{R} \$ 1.165,11$ & \multirow{2}{*}{$10,96 \%$} & $\mathrm{R} \$ 931,96$ & \multirow{2}{*}{$1,02 \%$} \\
\hline $21 / 8 / 06$ & Venda & $\mathrm{R} \$ 1.292,81$ & & $\mathrm{R} \$ 941,46$ & \\
\hline $13 / 09 / 06$ & Compra & $\mathrm{R} \$ 1.292,81$ & \multirow{2}{*}{,$- 096 \%$} & $\mathrm{R} \$ 941,46$ & \multirow{2}{*}{$-1,04 \%$} \\
\hline $15 / 9 / 06$ & Venda & $\mathrm{R} \$ 1.280,40$ & & $\mathrm{R} \$ 931,67$ & \\
\hline $27 / 9 / 06$ & Compra & $\mathrm{R} \$ 1.280,40$ & \multirow{2}{*}{$8,13 \%$} & $\mathrm{R} \$ 931,67$ & \multirow{2}{*}{$7,03 \%$} \\
\hline $20 / 10 / 06$ & Venda & $\mathrm{R} \$ 1.384,50$ & & $\mathrm{R} \$ 997,17$ & \\
\hline $6 / 11 / 06$ & Compra & $\mathrm{R} \$ 1.384,50$ & \multirow{2}{*}{$14,41 \%$} & $\mathrm{R} \$ 997,17$ & \multirow{2}{*}{$1,66 \%$} \\
\hline $30 / 11 / 06$ & Venda & $\mathrm{R} \$ 1.584,00$ & & $\mathrm{R} \$ 1.013,72$ & \\
\hline \multicolumn{3}{|c|}{$\%$ acumulada } & $58,40 \%$ & & $1,37 \%$ \\
\hline
\end{tabular}

Fonte: simulação elaborada pelos autores a partir dos indicativos de compra e venda do Metastock (2006). 
Como se observa na Tabela 10, se um investidor tivesse aplicado R \$ 1.000 nas ações da WEG (WEGE3) em 15/03/06 e as tivesse vendido em 30/11/06 obteria uma rentabilidade de 58,40\% (R\$ $1.584,00)$ contra uma rentabilidade de $1,37 \%(\mathrm{R} \$ 1.013,72)$ de uma suposta carteira de ações que segue a valorização do IBOVESPA.

\section{CONCLUSÃO}

A partir de 2006, houve aumento considerável de investidores que passaram a operar na BOVESPA, principalmente via home broker. A partir dessa constatação, torna-se salutar a análise de ferramentas que auxiliem esses investidores no processo decisório de compra ou venda ações. Entretanto deve ser destacado que esses indicativos apresentam certo atraso, não mostrando exatamente o momento ideal para entrar ou sair do mercado acionário, ou seja, é aí que deve entrar o feeling do investidor para determinar qual será o melhor momento de entrada ou saída que maximize seu investimento, de acordo com as estratégias e objetivos traçados por ele.

Dentre as cinco empresas analisadas durante o ano de 2006 foi constatado que o MACD é uma ferramenta eficaz, pois os indicadores de compra e venda proporcionariam aos investidores uma rentabilidade média acumulada de $26,7 \%$ contra uma rentabilidade média acumulada do Ibovespa de $0,90 \%$. Além disso, os indicadores, entre determinado momento de compra e venda, foram em média favoráveis em $58,3 \%$ e desfavoráveis em $41,7 \%$.

Não obstante, o fato de um investidor utilizar somente uma ferramenta, não garante que ele sempre obtenha retornos positivos em seus investimentos. É interessante e aconselhável que o investidor utilize mais de uma ferramenta, seja o Índice de Força Relativa, o On Balance Volume, o Estocástico e etc. como indicativos complementares ao processo de tomada de decisões dos investidores.

O mercado acionário é extremamente volátil e intempestivo, ou seja, ganhos passados não refletem necessariamente ganhos futuros; portanto a utilização de ferramentas que auxiliem os investidores na escolha de ações que potenciem seus ganhos é pertinente e ajudam a consolidar o mercado de capitais nacional.

Artigo recebido em 27.06.2007. Aprovado em 25.06.2008.

\section{REFERENCIAS BIBLIOGRÁFICAS}

Appel, G. (2005). Technical analsysis. Upper Saddle River: Person Education.

Banco do Brasil. (2007). História. Recuperado em 23 maio, 2007, de http://www.bb.com.br/portalbb/page1,136,3527,0,0,1,8.bb?codigoNoticia=691\&codigoMenu=1 065

Bolsa de Valores de São Paulo. (2006). Novo mercado: Bovespa Brasil. Recuperado em 25 maio, 2007, de http://www.bovespa.com.br/pdf/Folder_NovoMercado.pdf

Brum, C. A. H. (2006). Aprenda a investir em ações e a operar na bolsa via internet (3a ed.). Rio de Janeiro: Ciência Moderna.

Elder, A. (2004). Como se transformar em um operador e investidor de sucesso. Rio de Janeiro: Campus.

Elder, A. (2006). Aprenda a operar no mercado de ações (7a ed.). Rio de Janeiro: Campus. 
Eletromotores WEG. (2007). Isto é WEG. Recuperado em 17 maio, 2007, de http://www.weg.com.br/asp/system/empty.asp?P=173\&VID=default\&SID=303487516654614 $\& \mathrm{~S}=1 \& \mathrm{~A}=$ closeall $\& \mathrm{C}=26830$

Empresa Brasileira de Aeronáutica. (2007). Perfil. Recuperado em 23 maio, 2007, de http://www.embraer.com.br/portugues/content/empresa/profile.asp

Fortuna, E. (2002). Mercado financeiro (15a ed.). Rio de Janeiro: Qualitymark.

Freund, J. E., \& Simon, G. A. (2000). Estatística aplicada: economia, administração e contabilidade. (9a ed.). Porto Alegre: Bookman.

Natura. (2007). Perfil da organização. Recuperado em 12 junho, 2007, de http://natura.infoinvest.com.br/static/ptb/perfil_organizacao.asp?language=ptb

Noronha, M. (1995). Análise técnica: teorias, ferramentas e estratégias. Rio de Janeiro: Editec.

Matsura, E. (2007). Comprar ou vender?Como investir na bolsa utilizando análise gráfica (5a ed.). São Paulo: Saraiva.

Metastock. (2006). (Versão 10.0) [Software]. Salt Lake City, UT, USA: Equis International.

Perdigão Agroindustrial. (2007). A empresa. Recuperado em 12 junho, 2007, de http://www.perdigao.com.br/empresasperdigao/paginas.cfm?area $=0 \&$ sub $=1$

Pinheiro, J. L. (2005). Mercado de capitais (3a ed.). São Paulo: Atlas. 